Viso - Cadernos de estética aplicada Revista eletrônica de estética

ISSN 1981-4062

$N^{0} 15,2014$

http://www.revistaviso.com.br/

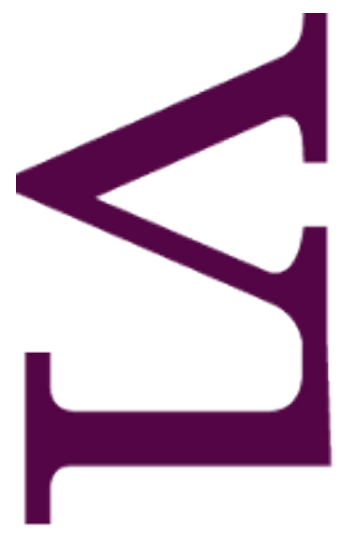

ڤ
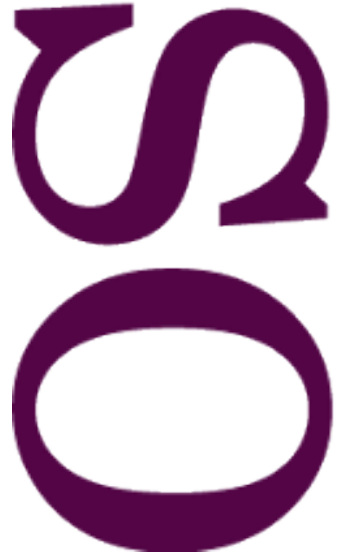

\title{
Ilhas perdidas: algumas considerações sobre o capítulo "Entre o mar e o continente", de Marco Antonio Casanova
} Fernando Barros 


\section{RESUMO}

Ilhas perdidas: algumas considerações sobre o capítulo "Entre o mar e o continente", de Marco Antonio Casanova

O breve texto que se segue visa a comentar o capitulo "Entre o mar e o continente", de Marco Antonio Casanova. Implicando passar em revista importantes pontos teóricos de sustentação - cujas referências vão de Nietzsche a Heidegger -, mas também movimentos artísticos contemporâneos de suma relevância - como, por exemplo, a "act painting" praticada por Pollock -, o texto que se nos ofereceu à leitura acumula desafios extremamente instigantes. Obrigando-nos a repensar os desempenhos de nosso sistema perceptivo, bem como a nossa relação com o passar do tempo, o problema que ele nos propõe deixa-se resumir numa pergunta lapidar, a saber: qual é a relação entre a arte abstrata e o modo contemporâneo de existência?

Palavras-chave: temporalidade - pintura de ação - instante - existência

\section{ABSTRACT}

Forgotten Islands: Some Notes on the Chapter "Between sea and continent", by Marco Antonio Casanova

The following short piece aims at commenting Casanova's chapter entitled "Between sea and continent". Inspecting important theoretical points of definition - whose references go from Nietzsche to Heidegger -, as well as highly significant contemporary art movements - like Pollock's "act painting", for instance -, the text read by us put up extremely intriguing challenges. Impelling us to rethink the performances of our perceptive systems, as well as our relationship to time itself, the problem which it poses can be summed up as follows: what is the relation between abstract art and contemporary mode of existence?

Keywords: temporality - act painting - instant - existence 
BARROS, F. "Ilhas perdidas: algumas considerações sobre o capítulo "Entre o mar e o continente", de Marco Antonio Casanova". In: Viso: Cadernos de estética aplicada, v. VIII, n. 15 (jan-dez/2014), pp. 192-200.

DOI: 10.22409/1981-4062/v15i/184

Aprovado: 14.08.2014. Publicado: 31.01.2015.

(C) 2014 Luisa Buarque. Esse documento é distribuído nos termos da licença Creative Commons Atribuição-NãoComercial 4.0 Internacional (CC-BY-NC), que permite, exceto para fins comerciais, copiar e redistribuir o material em qualquer formato ou meio, bem como remixá-lo, transformá-lo ou criar a partir dele, desde que seja dado o devido crédito e indicada a licença sob a qual ele foi originalmente publicado.

Licença: http://creativecommons.org/licenses/by-nc/4.0/deed.pt_BR

Accepted: 14.08.2014. Published: 31.01.2015.

(c) 2014 Luisa Buarque. This document is distributed under the terms of a Creative Commons Attribution-NonCommercial 4.0 International license (CC-BY-NC) which allows, except for commercial purposes, to copy and redistribute the material in any medium or format and to remix, transform, and build upon the material, provided the original work is properly cited and states its license.

License: http://creativecommons.org/licenses/by-nc/4.0/ 
Dividido em parágrafos que indicam uma articulação notadamente experimentada, o texto "Entre o mar e o continente" começa in media res, compondo um capítulo de uma reflexão incomparavelmente mais abrangente ${ }^{1}$ - a qual, já nos desculpamos aqui, não tivemos a oportunidade de acompanhar antes do presente encontro. ${ }^{2}$ Salta aos olhos, de quem o lê, que importantes conceitos e pregnantes operadores teóricos são introduzidos a partir de passos argumentativos que se referem a ponderações previamente maturadas. Se isso acumula a vantagem de permitir a mobilização imediata de ideias seminais - como, por exemplo, a de "eterno retorno", em Nietzsche; "ser-o-aí", em Heidegger; e "intuição eidética", em Husserl - por outro lado também dá ensejo, à imaginação do leitor desavisado, a voos temerários. Cientes das possíveis extravagâncias motivadas por tal abertura interpretativa, mas sem deixar de explorá-la em termos de sua efetividade hermenêutica, contamos, a seguir, tão-somente localizar possíveis "ilhas perdidas" entre o mar e o continente descerrados texto adentro.

Logo no primeiro parágrafo, mais descritivo e condensado, o texto dá a conhecer uma mudança de paradigma operada pela arte contemporânea, cuja radicalidade converteu-a num tipo de divisor de águas, alterando em profundidade o sentido e o alcance de nosso universo sensível. À guisa de ilustração, o autor traz à baila, entre outros, o sortilégio anarcodadaísta, a recomposição não racional cubista, o surrealismo, o concretismo e o expressionismo do grupo Der blaue Reiter - apontando Kandinsky, inclusive, como o paladino deste último. Que as vanguardas líricopulsionais inseriram a arte no dia a dia, gerando novas formas de motricidade e inovadores eventos sensoriais, eis algo que salta aos olhos de quem lê textos célebres sobre o tema. Aqui, vários horizontes especulativos poderiam ser sondados. Do "declínio da aura" em Benjamin ${ }^{3}$, que indica de modo lapidar a subtração do culto de que a obra de arte era vetor e instrumento, até o posicionamento afirmado por Arthur Danto 4 , para quem a pretensa "abstração" da moderna obra de arte se deixa esclarecer mais e melhor pelas teorias que lhe dão amparo, e não pela ilusão de uma espécie de arte como que desvinculada do mundo. Afinal, deixando de tratar o sensível como um sistema de signos semanticamente explicáveis e implicando a reorganização completa de nossa cinestesia, a moderna obra de arte, para lembrar o fino comentário de Gérard Lebrun a esse propósito, "não convidava mais o seu receptor a sonhar com base nela, mas a analisar a sua percepção a partir das indicações que the fornecia". ${ }^{5}$

Sem vincular tais mutações a algum referencial teórico específico, o texto trata de introduzir duas questões "de fôlego", a saber: "Bem, mas qual o lugar da arte abstrata para nós? Qual a relação entre a arte abstrata e o modo de ser do existir contemporâneo?" Intercalando tais perguntas com análises detalhadas de imagens materiais - com as quais o inteiro texto é apetrechado - a ponderação ousa então fornecer uma primeiríssima resposta. Assim é que se lê mais adiante: "De início de maneira algo injustificada, podemos dizer simplesmente que a arte abstrata é por essência o campo de articulação do modo de ser e da temporalidade propriamente dita do existir humano". Com isso, o ensaio faz intervir uma problemática que se acha noutro 
plano, qual seja, o da (in)determinação temporal. Sob a égide dessa inflexão, surgem então, desde logo, novas perguntas: "Como pensar o tempo do abstrato e articulá-lo com a temporalidade do instante frágil e eterno que ganhou voz pela primeira vez em meio à tentativa impressionista de captura do instante feliz?" E, imediatamente depois, mais uma indagação. Desta feita, com mais uma inflexão. Ei-la: "Comecemos com mais uma pergunta: qual o lugar da paisagem na pintura ocidental?" Deixando aparentemente de lado a primeira pergunta - sobre um possível vínculo umbilical entre a arte abstrata e a dita temporalidade do "existir humano" - o texto se detém, então, no tema da paisagem. Para tanto, discorre sobre o Renascimento e, em especial, sobre a lei matemática que dele nasce e cresce. Passadas várias linhas, porém, nota-se que o mais relevante mesmo, em tal patamar reflexivo, é ainda a questão relativa à temporalidade - razão pela qual, em nosso entender, o problema da paisagem termine por adquirir um sentido mais estratégico do que estrutural propriamente dito. Até porque tal tema acaba levantando outras questões de fundo - tanto mais complexas e de longa marcha na história da filosofia, porquanto dizem respeito ao problema da unidade e, em especial, da separação entre homem e mundo. Tanto é assim que, logo em seguida, lê-se: "por mais que se tentasse resolver o problema da unidade, jamais se conseguia plenamente superar o fosso entre o homem e o seu espaço existencial".

O caminho entrevisto pelo autor para dar uma saída a tais aporias e, por fim, retornar àquilo que, em rigor, constitui a espinha dorsal de sua ponderação - i. e., a relação entre temporalidade e arte abstrata - é o da suspensão heideggeriana da distância entre o existir e o próprio espaço existencial. A esse respeito, ele escreve: "Não há nenhuma possibilidade de cindir aqui interior e exterior, de tal modo que o existir se descobriu agora radicalmente marcado pelo espaço-entre no qual o ser-aí insistentemente é". Desfeito, pois, o problema da pretensa cisão entre homem e mundo - mas não sem antes avisar o leitor que, embora o homem faça parte de uma totalidade que nele se expressa, ainda assim poderá ser mantida, regulativa e metodologicamente, uma certa distância entre particular e universal -, o texto trata então de afirmar uma indelével relação originária do ser-o-aí com o mundo. Relação essa, diz-nos o texto, "que não tem de modo algum como ser às últimas consequências rompida". É justamente esse vínculo inquebrantável que será associado à arte contemporânea - sobretudo, à produção de Paul Klee e à obra "Guerra Fria", de Jackson Pollock. É por essa via que, aos poucos, a problemática temporal volta à tona. Assim se lê: "[...] é fundamental deixar que os quadros de Pollock e de Klee nos falem sobre o tempo que ganha corpo neles". No entanto, como uma espécie de necessidade interna da argumentação, outras questões são novamente levantadas a partir do trabalho levado a cabo por tais artistas. Por exemplo: "Como é possível ver unidade em um amontoado de linhas que formam um emaranhado inextrincável de ramificações e de pontos de interseção?" Ora, tendo diante dos olhos o sentido pontual da argumentação, que evoca as noções de "linha" e "ramificação" - e levando ainda em conta, antes de mais nada, que a referência principal a essa altura da ponderação é a filosofia de Heidegger -, parece-nos que seria instigante, aqui, a utilização de outros conceitos heideggerianos, para além daqueles 
contidos em Ser e tempo. Como, por exemplo, a ideia de "traço" ou "rasgo" [Riss] presente em $A$ origem da obra de arte. Pródiga, a associação poderia lançar outras luzes sobre a operosidade artística contemporânea, porquanto diz respeito à instauração da própria forma sensível - de uma Gestalt, mais precisamente - no seio do conflito [Streit] entre terra e mundo, de cujos respectivos fechamento e abertura decorreria uma forma original, um traço único impresso pelo artista. E aqui o melhor mesmo é citar o pensador da Floresta Negra: "A forma [Gestalt] é o conflito trazido para o traço, o qual é recolocado e, a ser assim, firmemente estabelecido na terra". ${ }^{6}$

É bem verdade que o texto não pretende inserir elementos exteriores às obras, haja vista que espera analisá-las, por assim dizer, a partir delas mesmas, sem desvios. "Como aconteceu aqui incessantemente", adverte-nos Casanova, "o que nos interessa não é uma vez mais a inserção de elementos estranhos ao quadro [...] Ao contrário, todo o nosso esforço também está voltado nesse caso para a concentração da atenção naquilo que temos diante de nós e naquilo que a partir daí nos é dado perceber". Com isso, o texto deixa ecoar, com força, uma abordagem de cunho fenomenológico. E é mesmo a partir de um fenomenalismo seguro, inventivo e, digamos, "empírico" que as obras arroladas passam a ser dissecadas texto adentro. Razões bastantes para que, mais adiante, seja dito ainda: "Nossa relação com os entes não é originariamente mediada por uma sensibilidade capaz de intuir formas, por exemplo, mas nossa relação é antes originariamente ideadora, para usar um termo caro à fenomenologia".

Com efeito, a julgar pelo espírito e pela letra do texto, esse caminho surge mesmo como o mais acertado, condizente com aquele que espera ater-se, para além da semiótica, àquilo que as imagens nos "falam". Que a fenomenologia prestou uma valiosa contribuição à análise das chamadas imagens materiais (quadros, desenhos, fotos etc.), eis algo que salta aos olhos de quem percorre a história da filosofia contemporânea. Ao visar a uma eidética da imagem, deteve-se na estrutura imagética tal como aparece à intuição reflexiva, mas sem arrastar consigo os pesados compromissos metafísicos contidos na teoria clássica da imagem. É justamente sob o influxo de tal orientação que ganha relevo, por exemplo, a questão empreendida por Sartre em A imaginação: "O que é uma imagem? Esse elemento tão importante da vida psíquica terá uma estrutura essencial acessível à intuição e que possa ser fixada por meio de palavras e conceitos?"

Ora, o característico de uma personagem efigiada num quadro não é tanto o fato de ela não ser perceptível tal como a pessoa "real", mas ser efetivamente perceptível a despeito de sua irrealidade - indicando que, para compreender as imagens, cumpre deixar de lado a dicotomia ardilosa: signo/significação. E, no fundo, seria preciso abandonar a crença de que todas as imagens pertencem à classe dos signos, aceitando de bom grado que entre estes últimos e a significação não há distância alguma. Como bem lembra Lambert Wiesing a esse respeito: "mesmo se o caráter imagético fosse sempre indicado mediante imagens, isso não seria suficiente para fundamentar a ideia de que tal caráter constitui um atributo essencial da imagem - quer dizer, um atributo do qual 
nenhuma imagem pode abrir mão". 8

Mas, voltemos ao ensaio de Casanova, visando àquilo que, em última análise, constitui sua verdadeira força questionante, a saber, a questão da temporalidade. Assim é que, abrindo uma página filosófica cara aos nietzschianos, o texto segue adiante:

Como procuramos salientar a partir do pensamento do eterno retorno do mesmo [...] a reconciliação entre tempo e eternidade acontece aí sobretudo em função da supressão de toda distância entre passado, presente e futuro [...] No último momento de sua atividade criadora [...] Nietzsche começa a escrever coisas como 'eu sou todos os nomes da história'. O cerne de tais afirmações não é outro senão o cerne mesmo do eterno retorno do mesmo.

Aqui cumpre fazer uma breve glosa. Nem mesmo em Assim falava Zaratustra a ideia do retorno é unívoca, achando-se ausente, por exemplo, em todo o primeiro Zaratustra. Como dirá Marco Brusotti a esse propósito: "Mesmo a decisão literária fundamental de comunicar o eterno retorno no contexto de Assim falava Zaratustra foi uma decisão a que Nietzsche chegou somente após o primeiro 'Zaratustra". ${ }^{9}$ Recebendo diversas formulações ao longo da obra e exigindo leituras diacrônicas por parte de seus intérpretes, a ideia de retorno, em Nietzsche, não se limitaria à sua versão cosmológica ou metafísica.

Não se trata, aqui, evidentemente, de soterrar o estímulo vital da interpretação com questões de ordem técnica ou exegética, mas resta que o próprio ensaio de Casanova teria a ganhar ao explorar outros patamares reflexivos por meio da ideia de eterno retorno. Como imperativo ético, por exemplo, esta última nos forçaria a dar um sentido ímpar a nossas ações. Ineficaz face ao fluxo polimórfico da transitoriedade, àquilo que, ao vir a ser, não se deixa mais capturar ou fixar, o universo volitivo humano tenderia a tomar sobre si a perspectiva de um padrão reativo, relacionando-se de um modo negativo com o passado. "Impotente em relação àquilo que está feito", para lembrar aqui as palavras de Zaratustra, a vontade seria sempre "um espectador ruim de todo o passado". ${ }^{10}$ Sob tal ótica, a vingança contra o tempo consistiria, antes de mais nada, numa forma específica de repulsa ou aversão contra a existência já vivida e transcorrida. Ora, se a pintura de Pollock foi chamada pelos críticos de "act painting", pintura de ação, é justamente porque não se trata, nesse caso, de uma pintura passiva e premeditada, senão que de uma atividade que vem a ser em sendo, de sorte que o tempo da pintura ativa está sempre avançando. Se algo não sai conforme o esperado, a vontade do pintor é, para ecoar uma vez mais a expressão do alter ego de Nietzsche, "impotente em relação àquilo que está feito". Pressupondo coragem e uma boa dose de anuência ao vira-ser, a pintura aqui se vê obrigada a fazer as pazes com o passar do tempo, o qual leva o pintor a ir do começo ao fim, da primeira borrifada até o último pingo de tinta sobre a tela, afirmando tudo o que se delineia, as linhas mais sublimes, mas também os gestos mais desenfreados. 
O texto não se furta, é claro, a pensar a fundo essa pontualidade da ação, mas espera fazê-lo a partir de uma outra visada sobre a temporalidade, abordando uma espécie de bifrontismo que, segundo o autor, cruza e constitui a própria noção de instante. Nesse sentido, lê-se: "Não há o instante enquanto temporalidade própria [...] O que há, inversamente, é uma apreensão alienada do tempo, a suposição de que haveria o tempo para além do instante. Tempo alienado da existência e tempo propriamente dito do existir: dois modos diversos de experiência do instante". Contínuo sucessivo, o fluxo temporal deixa-se dividir ao infinito, seccionando-se em momentos cada vez sutis e indelineáveis - onde cada ínfimo instante é devorado para, logo em seguida, ser suprimido por outros "átomos" de tempo -, de modo que uma representação conceitual completamente fiel do passar do tempo parece estar, em princípio, fora de questão. 0 tempo, no fundo, não poderia ser definido em termos de tempo, como sendo, ele mesmo, uma porção de tempo. E eis, aí, o problema central com o qual nos deparamos - muito bem reconhecido, por outro viés, pelo texto de Casanova. Ou rechaçamos o aspecto físico-exato do tempo e acabamos legitimando o triunfo da subjetividade alienada, ou, então, arriscamo-nos a reiterar uma noção de tempo "absoluto", assimilável àquele afirmado pela física clássica - sem idade e duração, passado ou futuro. É justamente aqui que a arte pode e deve intervir, dando-nos a conhecer um tempo mais digno, durável em termos de um "eu" que não se dobrou totalmente à espacialização físicomecânica, a um "ego" que não se deixou vampirizar, por assim dizer, pelas máquinas ao seu redor, as quais insistem em reduzi-lo à condição de peça de relógio.

Ao encontrar essa temporalidade "salvífica" no coração pulsante do fazer artístico, o ensaio de Casanova termina por descerrar uma dimensão que suplanta os estudos estéticos, expondo a céu aberto um conflito que se acha na base de nossa própria existência. Perguntamo-nos, porém, à guisa de conclusão, se não for falar mais do que o necessário, se não seria igualmente importante inserir tal análise num horizonte histórico mais amplo, operando, por exemplo, com o processo que Helmuth Plessner chamou de "musicalização dos sentidos"11 - processo programaticamente mais explícito em Kandisnky e Franz Marc, mas com raízes igualmente profundas no romantismo musical alemão. Isso porque, no final das contas, o capítulo "Entre o mar e o continente" se resolve em metáforas musicais, delineando, à sua maneira, uma pseudomorfose das artes plásticas à música. ${ }^{12}$ Tanto é assim que se lê: "O pintor torna-se pintor apenas por meio da escuta à necessidade que a cada vez se apresenta no movimento mesmo da pintura. O projeto da obra emerge da própria dinâmica da escuta". E, detendo-se numa obra de Klee, sugere ainda: "Talvez seja mesmo por isto que Klee chama o quadro de 'som antigo'”. Nesse sentido, o ensaio renova e atualiza as sábias palavras de Gérard Lebrun, com as quais encerramos, aqui, essas breves e insulares considerações: "O olho fora educado para olhar", mas agora, "propunham-Ihe que escutasse". ${ }^{13}$ 
${ }^{1}$ Cf. CASANOVA, M. A. Eternidade frágil: ensaio de temporalidade na arte. Rio de Janeiro: Via Verita, 2013.

$27^{\circ}$ Encontro Nacional do GT de Estética da ANPOF - de 27 a 29 de maio de 2014, na UFF.

${ }^{3}$ Cf. BENJAMIN, W. "A obra de arte na era de sua reprodutibilidade técnica. Primeira versão". In: Obras escolhidas. Magia e técnica, arte e política. Tradução de Sergio Paulo Rouanet. São Paulo: Brasiliense, 1994, pp. 165-196.

${ }^{4}$ Cf. DANTO, A. "O mundo da arte". In: O belo autônomo. Textos clássicos de estética. Tradução de Rodrigo Duarte. Belo Horizonte: Autêntica, 2012, pp. 315-334.

${ }^{5}$ LEBRUN, G. "A mutação da obra de arte". In: A filosofia e sua história. São Paulo: Cosac Naify, 2006, p. 338.

${ }^{6}$ HEIDEGGER, M. Der Ursprung des Kunstwerkes In: Holzwege. Frankfurt am Main: Klostermann, 2003, p. 51.

${ }^{7}$ SARTRE, J.-P. A imaginação. Tradução de Luiz Roberto Salinas Fortes. Rio de Janeiro: Bertrand Brasil, 1989, p. 106.

${ }^{8}$ WIESING, L. "Sind Bilder Zeichen?" In: SACHS-HOMBACH, K.; REHKAMPER, K. (orgs.) Bild, Bildwahrnehmung, Bildverarbeitung. Wiesbaden: DUV, 1998, p. 95.

${ }^{9}$ BRUSOTTI, M. "O eterno retorno do mesmo em Assim falou Zaratustra". Tradução de Rogério Lopes. In: Estudos Nietzsche , v. 3, n. 2 (jul/dez 2012), pp. 149-167, aqui p. 152.

10 NIETZSCHE, F. Also sprach Zarathustra. In: Werke. Kritische Studienausgabe (KSA). Berlim/Nova York: Walter de Gruyter, 1999, v. 4, p. 180.

11 Cf. PLESSNER, H. "Die Musikalisierung der Sinne. Zur Geschichte eines modernen Phänomens”. In: Gesammelte Schriften VII. Frankfurt am Main: Suhrkamp, 2003, pp. 479-491.

${ }^{12}$ Seguimos aqui, igualmente, o comentário de Helmuth Plessner. Cf. Ibidem, p. 490.

${ }^{13}$ LEBRUN, G. . Op. Cit., p. 338. 